\title{
Poetry
}

\section{Words of disclosure}

You said it was bad

News you had

For me, words to help

Explain my brother's

\section{"Adverse event,"}

Said swiftly, to avoid

The heaviness that chased

Those words, to blunt

The news of his

\section{"Unanticipated outcome,"}

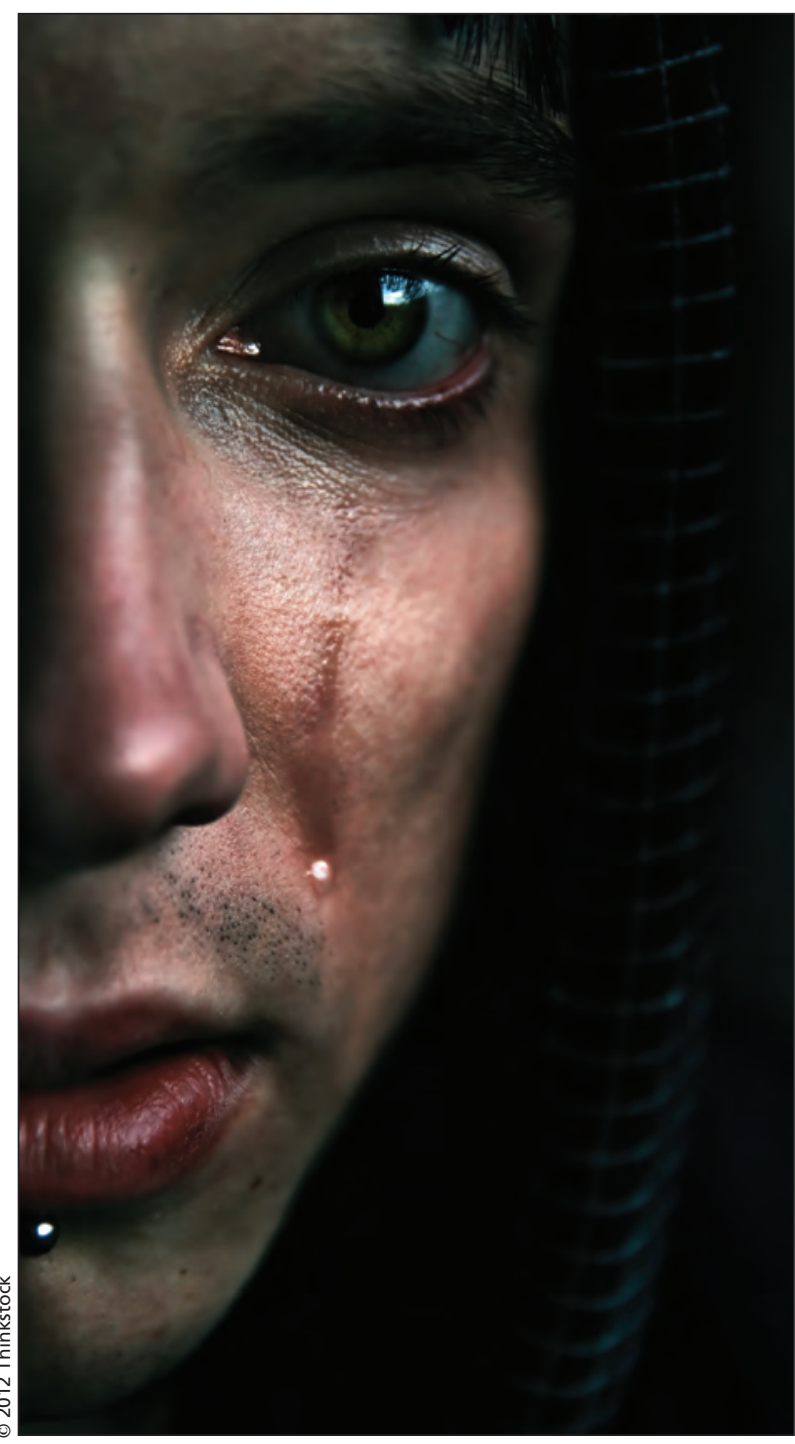

Your gaze fleeing

Mine, scanning

The ground to find

Reprieve from your

$$
\text { "Error," }
$$

With assurance too

Thin and sterile to

Stop fear from escaping

Through your voice.

But I had no

Words, no way to hear

Your careful reasons

For your mistake

\section{When I was stunned}

By those foreign words, cold

Against my chest like the first touch

From a searing iron,

Before the questions and even

The confusion; cold before

The heat tunneled through,

drawing out painful breaths.

You said it was bad

But I felt worse,

That despite those words, I couldn't Feel your regret, your Humanity beside mine, Afraid of the moment, but present;

That you disclosed

And informed, even

Discussed the details,

Without "sorry;"

That by your words, I felt

Boxed in and stranded, With you in that room, but still Alone.

\section{Joshua Liao MD}

Baylor College of Medicine

Houston, Tex.

CMAJ 2012. DOI:10.1503/cmaj.120508 